\title{
INVESTIGACIÓN/RESEARCH
}

\section{EL ESPACIO QUE DISPONE LA PRENSA GRÁFICA PARA LOS ARTÍCULOS DE LOS REFERENTES DE LAS CIENCIAS SOCIALES}

Cecilia Blanco Berrone ${ }^{1}$ : Universidad Nacional de Córdoba (Córdoba). Argentina. berrone.cecilia@gmail.com

Liliana E. Pereyra Gómez: Universidad Nacional de Córdoba (Córdoba). Argentina. Ipereyra@eco.unc.edu.ar

\section{RESUMEN}

Los hechos sociales requieren, habitualmente, de una comprensión y explicación desde las Ciencias Sociales. Los problemas de la sociedad invitan a los científicos sociales a participar, con sus análisis, investigaciones e interpretaciones teóricas, en algunos medios gráficos. En este trabajo nos propusimos estudiar de manera exploratoria, cuál es la relación existente entre los artículos de los científicos sociales y el espacio o lugar que aquellos ocupan en la estructura de los diarios El País (de España) y La Nación (Argentina), en el período $1^{0}$ de abril al $1^{0}$ de mayo de 2011. Nos preguntamos, además, a qué disciplina pertenecen los autores publicados; cuáles de ellos desarrollan actividades académicas; qué temáticas se analizan. Los resultados muestran que si bien tanto las Ciencias Sociales como las Humanas mantienen una participación importante dentro del ámbito académico, su presencia en los medios gráficos no es tan evidente. Por el contrario, se observa que los artículos de los referentes en Ciencias Sociales, sean éstos resultados de investigaciones o análisis teóricos, suelen incorporarse en la sección del diario "Opinión", quedando desplazados, sistemáticamente, de la sección "Ciencia", donde solo caben artículos provenientes de científicos de las tradicionales ciencias duras.

PALABRAS ClAVE: Científicos sociales - Prensa gráfica - Investigación social Opinión

\footnotetext{
${ }^{1}$ Cecilia Blanco Berrone: Facultad de Derecho y Ciencias Sociales de la Universidad Nacional de Córdoba (Córdoba). Argentina.

Correo: berrone.cecilia@gmail.com
} 


\title{
PLACE ASIGNED IN THE PRESS TO ARTICLES WRITTEN BY SOCIAL SCIENTISTS
}

\begin{abstract}
Social facts habitually require an understanding and an explanation from the Social Sciences. The problems of society invite social scientist to participate, with their analyses, research and theoretical interpretations, in the graphic media. In this work, we set out to study, in an exploratory manner, the relation between the scientific articles by representatives of the Social Sciences and the place they are assigned in the newspapers El País (Spain) and La Nación (Argentina), in the period April 1 - May 1,2011 . We were also interested in finding out the disciplines the authors came from, which of them developed academic activities and what topics they were dealing with. The results show that although the Social and the Human Sciences have an important participation in the academic context, their presence in the press is not so evident. On the contrary, the articles by authors from the Social Sciences, whether they are about research results or theoretical analysis, are often placed in the Opinion section of the newspaper, thus being displaced, systematically, from the Science section, which is reserved only for articles from the traditional hard sciences.
\end{abstract}

KEY WORDS: Social scientists - Press - Social research - Opinion

\section{INTRODUCCIÓN}

En el contexto Latinoamericano, la participación del público/ciudadano en relación con las controversias que generan los resultados de la investigación científica es baja. Lo anterior, debido, en principio, a la relativamente escasa circulación de información referida a la temática. Algunos datos arrojados por la Segunda Encuesta Nacional de Percepción Pública de la Ciencia, realizada en el año 2007, muestran que, por ejemplo, 6 de cada 10 personas no conocen ninguna institución que se dedique a la actividad científica y que, la mayoría de los encuestados entiende que las vías predominantes de acceso a este tipo de información son el periodismo y los medios de comunicación masivos (SECYT, 2007).

Según Prenafeta (2008), hay en la actualidad una escasa presencia de producción científica en la prensa diaria, hecho que muestra la dificultad existente de establecimiento de diálogo entre la comunidad especializada y la ciudadanía. Por otra parte, la selección que hacen los periódicos respecto del tipo de información o artículo que deciden publicar, implica en mayor o menor grado, la imposición, para el público, no sólo del temario social sino además de cómo debe pensar. Los medios de comunicación masivos son aparatos ideológicos constructores de la realidad (Gramsci, 1984c; Eliseo Verón, Pintos 2000) y el imaginario social. En función de cómo los medios tratan determinadas temáticas, es el modo en que las personas perciben tales temas. En este sentido, sostenemos aquí que la participación de la comunidad científica en la comunicación pública resulta vital para que la sociedad se convierta en 
participante activa de los procesos y cambios que generan los conocimientos científicos (Cabeza, Riffo y Sanhueza, 2008).

En la actualidad, algunos autores como Echeverría (2005) han redefinido a la actividad científica como si se tratara de una acción social de carácter revolucionaria y ligada a la tecnología. Según éste autor (2005, p. 10) "Ya no sólo se trata de investigar, sino que hay que generar desarrollos tecnológicos que deriven en innovaciones que se pongan en práctica en el mercado, en la empresa, en la sociedad." De esta manera, el modelo otorga a los tecnocientíficos (tales como ingenieros, técnicos, empresarios, políticos) un lugar preponderante en el espacio de producción de conocimientos. El incremento de inversión privada en el campo tecno científico contribuyó a supeditar el proceso de construcción de conocimientos a la lógica capitalista, transformando, esa producción en mercancía de dominio privado.

Ahora bien, independientemente de la lógica de funcionamiento de las instituciones que producen conocimiento, la comunicación pública de los resultados de las investigaciones de las Ciencias Sociales, está mediada por la relación tensa entre estas instituciones científicas y los medios masivos de comunicación. En este sentido, cada noticia ó informe de investigación o columna de interpretación que aparece en los medios, cada aparición o no de determinados comunicados escritos por referentes científicos, se debe a las políticas de comunicación institucional de los diferentes campos científicos, pero y al mismo tiempo, a factores como la configuración de la industria periodística (Cabrera y Aguilera 2005). La lógica de configuración y funcionamiento de los medios tienen relación con los ritmos laborales, pautas editoriales; formación de los periodistas (en ocasiones escasa e insuficiente) y las brechas entre el lenguaje vulgar y el lenguaje científico-académico.

Éstas lógicas contribuyen no solo a la desinformación por parte de los ciudadanos comunes, sino también, y al mismo tiempo, a la desconfianza de los científicos en los medios de comunicación y a un reducido interés en los referentes de las Ciencias Sociales. Particularmente, la difusión de los conocimientos en el área de las Ciencias Sociales y su imposición como legítimos en el imaginario social depende, de la relación que los cientistas sociales establezcan con los medios masivos. En síntesis, mientras las Ciencias Sociales tienen su propia manera de describir la realidad, desde diferentes enfoques y paradigmas, los medios de comunicación poseen una forma propia de utilizar los aportes de aquellas.

El objetivo principal de este trabajo es analizar un aspecto clave en la relación artículos de científicos - nuevos actores - sociales/espacio (estructura) en la prensa gráfica. En la primera parte nos proponemos mirar los conceptos que están en juego, seguidamente se detalla la metodología utilizada. En tercer término, se reúnen aspectos generales de los periódicos seleccionados, en cuarto lugar, el análisis de los resultados y en último lugar, la reflexión final.

\subsection{Aproximaciones conceptuales}

En América Latina, existe escasa literatura que se dedique a analizar de manera 
sistemática el complicado proceso de llevar los resultados de las investigaciones en las Ciencias Sociales a los medios masivos de comunicación. Nos detendremos por un momento en algunos aspectos que hacen a la Ciencia Social. La ciencia social se convierte, en la actualidad, en una institución más dentro del conjunto de las instituciones sociales y debe validar su presencia y emergencia, no sólo aportando "conocimiento verdadero" sobre los fenómenos que estudia sino dándose la misión de conformarse en una piedra angular para el autoesclarecimiento de los miembros de la sociedad a la cual dirige su mirada. Para Agnes Heller (en Lulo y Schuster, 2002, p. 183) "las Ciencias Sociales pueden influir en el comportamiento de los agentes sociales". Un razonamiento hermenéutico permitiría sostener que si la sociedad se constituye a partir de su autointerpretación, entonces la interpretación de los científicos sociales, de carácter más técnico y depurado, contribuiría a sostener, afianzar o bien a modificar esa misma comprensión. Ésta actividad contribuiría, según Lulo y Schuster (2002) a que la ciencia social pierda su carácter de inocente, al amparo de la supuesta necesaria y falsa neutralidad valorativa, sostenida por años por los investigadores positivistas.

Mientras el científico natural entiende a la historia de la disciplina como el resultado de un inmenso depósito de conocimiento, acreditado por la comunidad científica y sedimentado a los largo de los años, el investigador social, por el contrario, acude a la historia para entrar en dialogo con sus objetos a fin de comprenderlos. Antes que aplicar la noción de progreso a las Ciencias Sociales, es preferible desarrollar un dialogo, puesto que no puede haber un progreso definido en la conversación mantenida con el pasado" (Lulo y Schuster, 2002, p. 187-188)

Por otra parte, es necesario considerar que las Ciencias Sociales conforman en sí mismas un campo científico constituido, al mismo tiempo, por una serie de subcampos disciplinares. Los campos son, siguiendo a Bourdieu (2003) sub-universos en los que se incluyen los agentes y las instituciones que producen, reproducen o difunden la educación, la salud, la economía, la ciencia, el arte, la literatura, entre otros. Se trata de microcosmos, que, si bien se encuentran sometidos a las leyes generales del macrocosmos social, posee sus leyes inmanentes y disponen de autonomía parcial. Las coacciones externas del espacio social global son mediadas por la lógica propia del campo, el cual tiene la propiedad de "refractar" (p. 75), transfigurar y retraducir a aquellas convirtiéndolas, inclusive, en irreconocibles para los agentes que se encuentran en su interior (Bourdieu, 2003). Al igual que el espacio social, los campos son espacios de fuerzas y luchas por transformar el campo de fuerzas. La estructura que adopta el campo representa el estado de la relación de fuerzas o el estado de la lucha entre agentes e instituciones por la posesión y distribución del capital específico, que, acumulado en el transcurso de luchas anteriores, orienta las estrategias ulteriores (Accardo y Philippe, 1989). Se establecen así, dentro de cada campo, luchas simbólicas con el objetivo de monopolizar la violencia legítima (o autoridad específica) para conservar o subvertir la estructura de la distribución del capital específico (Accardo y Philippe, 1989). En los campos científicos lo que está en juego es la autoridad científica, es decir; la capacidad de imponer criterios de cientificidad. El capital específico puede consistir en títulos de grado o posgrado, publicaciones, cargos académicos, amistades y relaciones personales. Según Tenti Fanfani $(2007$, p. 215) el 
campo de las Ciencias Sociales se encuentra actualmente atravesado por múltiples conflictos. No se trata de un espacio unificado, sino fragmentado por tradiciones, disciplinas y redes institucionales que funcionan como mercados relativamente autónomos.

El control se ejerce no sólo desde afuera del campo intelectual, científico y cultural, a través de la demanda de servicios simbólicos, sino en su mismo interior. La pérdida de autonomía del campo tiene relación con la apropiación gradual y continua del mismo por parte de los medios de producción, difusión y consagración cultural. El polo de poder tecnocrático de la comunicación cumple un rol decisivo en el proceso de pérdida de autonomía (Tenti Fanfani, 2007).

Si bien a las Ciencias Sociales se les ha concedido, históricamente, una menor importancia que a las Ciencias Naturales, constituyen, según el World Social Science Report (2010, p. 286) , "el núcleo formador de futuros ciudadanos comprometidos con las problemáticas del mundo".

La ciencia social es relevante y los cientistas sociales pueden jugar un rol significativo en la esfera pública puesto que (Martinelli, 2010, p. 287):

a) Producen resultados científicos aplicando una metodología rigurosa y desarrollando teorías lógicas, consistentes y empíricamente válidas.

b) Forman comunidades de investigación sólidas y sostenibles que guardan autonomía de juicio y mantienen, ellas mismas, una distancia crítica respecto de los problemas sociales que se están estudiando.

c) Consideran a la ciencia social y la práctica política como dos formas diferentes de acción.

En este sentido, puede señalarse que la Ciencia Social, no es una forma de activismo político pero sí una empresa científica destinada a construir un tipo de conocimiento que es simultáneamente empírico y crítico.

"Uno de los roles relevantes de la ciencia social es la articulación de conceptos clave y modelos analíticos de construcción de la realidad social, para producir los descubrimientos empíricamente probados y desarrollar análisis de los fenómenos sociales y combatir los prejuicios" (Martinelli, 2010, p. 288).

En países en los que hay establecidas comunidades de ciencia social, la innovación de los conceptos sociológicos y la ampliación de este conocimiento ha producido un aumento significativo de los niveles de debate público, de la toma de decisión y la formulación de políticas en clave local, nacional y global de los problemas sociales.

Otra de las contribuciones importantes de las Ciencias Sociales es su discurso público. Las mismas ejercen influencia sobre las prioridades de las agendas públicas de la política y de los medios de comunicación en relación con los problemas sociales. Los problemas sobre los cuales los cientistas sociales se ocupan habitualmente difieren de aquellos considerados como centrales por parte de los que ocupan posiciones de 
poder y de los medios de comunicación (Martinelli, 2010).

Además, tanto en sociedades democráticas como no democráticas, el contenido y el discurso de la vida pública están, cada vez en mayor medida, determinados por los más media y los políticos. Los científicos sociales que entran en el juego del debate público son cada vez menos y menos capaces de controlar como sus opiniones son transmitidas y recibidas (Martinelli, 2010).

Un cuarto rol de la ciencia social es decir la verdad en la cara del poder. Esto incluye la formación de la opinión pública a partir de la clarificación de los problemas complejos y sus implicancias para la sociedad en general, desenmarscarando las relaciones de poder que subyacen y dan forma a la vida social (Bourdieu y Wacquant, 1992, en Martinelli, 2010) , y la evaluación crítica de las políticas y las ideologías de aquellos que se encuentran en el poder. Normalmente, las verdades que producen los cientistas sociales incomodan a quienes se encuentran en el poder, hecho que contribuye a que éstos intenten censurar los resultados de la investigación, silenciando a la ciencia.

En general, los especialistas de las Ciencias Sociales (o científicos sociales), trabajen éstos en el ámbito universitario ó en el ámbito público o privado de un estado, mantienen, con las sociedades contemporáneas, una relación compleja. Por una parte, pertenecen a las sociedades de las cuales provienen, es decir, son influidos por su evolución y desarrollo. Por la otra, son observadores privilegiados y constructores (modeladores) de los desarrollos y cambios que se producen en la sociedad. Esta conjunción dialéctica de influencias multidireccionales ubica a los científicos en una posición clave tanto en el espacio social como en los debates acerca de él. Los especialistas en Ciencias Sociales cumplen, en cualquier sociedad, las funciones de: "transmisores de conocimiento, expertos, observadores del fenómeno social y pensadores críticos" (World Social Science Report, 2010, p. 286).

¿Cómo los medios divulgan los aportes de los científicos sociales? Los aportes de los referentes de las Ciencias Sociales deben adaptarse a un formato periodístico. Particularmente, los géneros periodísticos son estructuras textuales-discursivas que contribuyen a organizar el trabajo periodístico; a guiar las expectativas de los lectores y a "ofrecer un menú diverso de piezas textuales, gráficas e icónicas que permitan captar la atención del público" (Rost, 2003, p. 1).

Según Lorenzo Gomis (2000, p. 5) "el periodismo ha encontrado también a lo largo de su historia unos géneros propios, nacidos de la interacción de novedades tecnológicas y necesidades sociales". Así encontramos una variedad de géneros periodísticos tales como el Periodismo Ideológico; de Opinión, Informativo, Explicativo, Científico.

El periodismo ideológico (Rost, 2003; Gomis, 2000), entiende al periódico como órgano de acción política ó tribuna de doctrina. En este tipo de estructura textual predominan los géneros argumentativos de opinión como la editorial, la crítica, el comentario y las columnas. A su vez, el periodismo de opinión tiene una relación directa con los estos textos argumentativos, los cuales expresan y demuestran, 
retórica y persuasivamente, la opinión de quien los firma. Quien firma se hace cargo de sus argumentos y se asume que es una persona "autorizada" para opinar sobre algún asunto particular, por su conocimiento específico; sus méritos académicos, científicos o su experiencia personal, profesional o laboral.

Mientras tanto, el periodismo informativo, que convive durante algún tiempo con el ideológico, surge a partir de la necesidad, por pate de los dueños de los diarios, de desarrollar empresas comerciales. Para llegar a un público más amplio, la prensa opta por presentar en sus páginas, no solo comentarios sino noticias con intención de informar.

El periodismo de explicación (Rost, 2003; Gomis, 2000), por su parte, se ubica a medio camino entre el periodismo de opinión e informativo. Se trata de un formato periodístico que pone en crisis la tradicional rígida división entre hechos (facts) y comentarios (comments). Basándose en los hechos, no pretende ni convencer, ni enjuiciar, ni generar determinada opinión en el público receptor. Las crónicas, las entrevistas, reportajes, informes especiales e investigaciones son algunos de sus géneros.

Por último, está el periodismo científico (Calvo, 2006). El mismo se propone brindar el conocimiento, resultado de investigaciones científicas, a la sociedad en general. Fuente de enseñanza y aprendizaje, su objetivo primordial es convertirse en una herramienta de alfabetización científica (por su fácil acceso a grandes grupos sociales con diferentes niveles educativos).

Interesa aquí establecer esta distinción debido a nuestro objeto de estudio. Estas disquisiciones teóricas invitan a plantearnos preguntas del tipo: los referentes de las Ciencias Sociales, ¿escriben solo artículos de opinión? Sus escritos, resultado de investigaciones sociales, ¿son tomados por el periodismo científico ó son desplazados a la sección opinión de la prensa?¿Aparecen en los diarios examinados artículos científicos escritos directamente por los referentes de las Ciencias Sociales?¿Existirán contribuciones de los investigadores sociales que sean utilizadas por el periodismo de explicación? Éste tipo de preguntas, de un carácter teórico, dieron origen, en parte, a este trabajo empírico.

Por otra parte, resulta indispensable plantear el concepto de autor modelo de Eco (1987) como hipótesis interpretativa, puesto que el sujeto es el resultado de una estrategia textual del autor empírico. El autor asume que existe un sujeto empírico que quizá deseaba, pensaba o deseaba pensar algo diferente de lo que el texto le proponía a su lector modelo. Sin embargo, siguen siendo importantes las circunstancias de la enunciación en la elección de un lector modelo, las cuales invitan a hipotetizar sobre las intenciones del sujeto empírico de la enunciación. Es decir, que en el proceso de creación de la enunciación, el autor pretende ejercer algún tipo de influencia sobre el comportamiento del lector.

Los medios de comunicación de masas, pueden ser vistos, desde la tradición crítica de investigación en comunicación, y desde el enfoque heredado de la economía política 
de la comunicación, como parte integrante de la estructura económica de una sociedad, la cual, a su vez, actúa como "superestructura ideológica" (Muñoz, 1995; Bergés, 2010). Los medios de comunicación son, con Bergés (2010) y Gramsci (1977), tanto constructores de hegemonía como facilitadores de la negociación de las relaciones de poder.

Siguiendo a Gramsci (1977) las normas sociales e ideológicas que hacen al funcionamiento de los medios de comunicación tienen relación con la ideología de los grupos dominantes una sociedad. Los medios de comunicación, ubicados en el orden de la sociedad civil, (Gramsci, 1984, p. 16), "forman parte del conjunto de organismos privados destinados a mantener, defender y desarrollar el frente teórico-ideológico de la clase dominante". Los intelectuales orgánicos, ó "empleados" del grupo dominante, que cumplen la labor de construir la hegemonía social, trabajan desde estos organismos, y la prensa en general es la parte más dinámica de esta estructura de difusión ideológica y de generación de consenso (Gramsci, 1977). Desde este lugar se constituye, para Gramsci (1984), la opinión pública y el consenso, única base posible para una auténtica hegemonía.

La consolidación de su actividad económica ha sido considerada, por los partidarios de la Sociedad de la Información (EC, 1994 y Gore, 1994, citados en Bergés, 2010) como el motor de crecimiento de las economías mundiales. Lo anterior debido fundamentalmente a que permiten diseminar las Nuevas Tecnologías de la Información y la Comunicación a escala global. La privatización de los medios de comunicación y el aumento indiscriminado de los servicios comerciales convierten a la industria mediática en un eslabón de la cadena de producción capitalista, que refuerza una gestión de los medios de comunicación liderada por los intereses económicos y empresariales, y niega la posibilidad de cumplir su rol de servicio público en pos del ejercicio del derecho a la información y a la libertad de expresión (de Mateo y Bergés, 2009).

Los medios, entendidos como estructuras ideológicas, actúan en la sociedad transmitiendo discursos que contribuyen a construir la realidad social. Los mismos construyen el sentido de los fenómenos sociales, el conjunto de creencias que orientan las interacciones e ideas sobre el mundo. Con Verón (1993) los medios construyen las representaciones sociales a partir de un producto (texto, imagen, gráfico), el cual es un fragmento y una manifestación material de la producción social de sentidos (o semiosis social). Los medios y los periodistas se definen, según Ortega y Humanes (2000, p. 63), por "su capacidad de hacer visible a la sociedad".

El flujo constante de mensajes modela marcos de referencia de sus públicos. Los medios, actores económicos e ideológicos, construyen activamente la hegemonía, al definir los problemas sociales y el sentido en que deben entenderse, al dar voz a ciertos actores y silenciar a otros. Se trata de instancias que guardan para sí "el poder de decir y significar" (Vasilachis de Gialdino, 1997). Funcionan legitimando y sosteniendo el status quo, aun cuando puedan dar lugar a discursos aparentemente contra hegemónicos. Las noticias, como producto, son el resultado de un proceso de producción, basado en una serie de operaciones concretas que implican la selección 
de ciertos acontecimientos en detrimento de otros; la jerarquización de cada nota en el proceso de su cobertura (qué despliegue tendrá, con cuánto espacio o tiempo contará), y el enfoque con el que se contará la historia (dónde se pondrá el énfasis, quién será consultado, qué voces se reproducirán y de qué modo) (Verón, 1983 y 1993).

En síntesis, y siguiendo a Bergés (2010),los medios de comunicación dependen, sine qua non, de la lógica empresaria del capitalismo globalizado, y aquellos que ocupan posiciones privilegiadas en este campo (el económico), disponen de un plus de fuerza simbólica y social que les permite imponer su discurso e intereses en los medios.

\section{METODOLOGÍA}

Toda investigación se inicia a partir del contacto con el conocimiento acumulado acerca del tema o problema a investigar. En la génesis de este trabajo, se recurrió a la estrategia de análisis documental (Sierra Bravo, 1996). Se identificaron y localizaron documentos relacionados con la temática de interés, se resumieron sus contenidos y se construyeron fichas electrónicas bibliográficas, que facilitaron la posterior recuperación de la información. La investigación documental fue acompañada con el marco teórico, logrando especificar el problema de investigación, establecer los criterios de muestreo, categorías temáticas y reconstruir la historia de los dos diarios nacionales seleccionados para el estudio.

Se utilizaron fuentes documentales empíricas directas, como las obras de Verón (1983; 1993), Gramsci $(1977 ; 1984)$ u otros autores de la comunicación y periodismo científico y fuentes de documentación. Las fuentes secundarias de información consistieron en una variedad de documentos escritos, entre los cuales se destacan los informes y estudios (surgidos de investigaciones anteriores); la prensa (artículos periodísticos que permitieron luego completar el análisis e interpretación de los datos).

Particularmente, la manera de construir categorías temáticas se llevo a cabo siguiendo los criterios del Análisis de Contenido. El análisis de contenido es una técnica cuantitativa de investigación que se basa en el estudio del contenido manifiesto de la comunicación (Hernández Sampieri, Fernández Collado y Baptista Lucio, 2000), y es útil, muy especialmente, para establecer comparaciones entre editoriales de periódicos o revistas. Se trata de una técnica que permite hacer apreciaciones sistemáticas sobre la ideología y el pensamiento político de diversos órganos de difusión, encontrar coincidencias y discrepancias y obtener información profunda sobre temas complejos. El mismo consiste en estudiar la realidad social o comunicacional mediante la observación y el análisis de los documentos.

En este trabajo nos basamos en el método de análisis temático de la comunicación, que tiene relación con el estudio del nivel semántico de cualquier discurso (Navarro y Díaz, 2007). La técnica, utilizada con frecuencia en sociología, ciencias políticas y comunicación social, consiste en determinar la frecuencia de aparición en los textos de ciertas categorías previamente definidas, tales como ideas, vocablos, o elementos gráficos de carácter diverso. Estas categorías son variables o indicadores que derivan 
del problema de investigación.

Según Berelson (1952, citado en Hernández Sampieri, Fernández Collado y Baptista Lucio, 2000) esta técnica permite: a) Describir tendencias en el contenido de las comunicaciones; b) Establecer las diferencias internacionales en materia del contenido; b) Comparar los medios o niveles de comunicación; c) Poner de relieve rasgos estilísticos. Mientras que Holsti (1969, citado en Hernández Sampieri, Fernández Collado y Baptista Lucio, 2000) por su parte, agrega que la técnica permite no solo describir las características de la comunicación en términos de qué se dice, cómo se dice y a quién se lo dice sino también formular inferencias en cuanto a los antecedentes de la comunicación, averiguando el por qué de lo que se dice

El universo de análisis en este caso particular es la totalidad de artículos publicados en las secciones Ciencia y Editorial de los diarios LA NACIÓN y EL PAIS en el período $1^{\circ}$ de abril al $1^{\circ}$ de mayo de 2011. La búsqueda de los textos se realizó a partir de los buscadores web de ambos periódicos, revisando las ediciones del periodo antes mencionado. En el caso de La Nación www.lanacion.com.ar/ y en El País... http://www.elpais.com/buscar/. Las unidades de análisis son los actores que escriben artículos para los diarios.

Las categorías de análisis fueron fundamentalmente las siguientes:

1) Temática y titulo de los textos

2) Autor

3) Fecha de publicación

4) Cantidad de textos

5) Sección

Finalmente se construyó una base de datos para extraer la frecuencia de aparición y los porcentajes de aquello de interés para el estudio. Esto permitió comparar los datos obtenidos para LA NACIÓN y EL PAÍS. En cuanto a las categorías del autor podemos decir que existen los especialistas de las Ciencias Sociales que pueden trabajar en el ámbito universitario, en el ámbito público y/o privado. Los cientistas, ó personas que confían plenamente en los principios y resultados de la investigación científica, y desarrollan una práctica rigurosa de sus métodos. Y Por otra parte, los referentes, mantienen una profesión y ejercen su disciplina (en el área de las Ciencias Sociales y Humanas) en el ámbito académico científico. En nuestro caso utilizaremos, en ocasiones, indistintamente los término científicos (ó cientistas) sociales y referentes de las Ciencias Sociales puesto que entendemos que los catedráticos hacen docencia pero, además, investigación científica.

\section{ANÁLISIS Y DISCUSIÓN}

\subsection{Aspectos generales de LA NACIÓN y El País}

\subsubsection{La Nación (Argentina)}


La Nación, fue fundado en 1870 por Mitre, militar, periodista y presidente argentino en 1862. En el acto fundacional, Mitre señaló que el periódico sería una tribuna de doctrina que bregaría por los principios de la Constitución Nacional de 1853 (cuyos orígenes se remontaban a los principios del liberalismo clásico de la jurisprudencia y doctrina política del federalismo estadounidense), y que serviría para interpretar la realidad y orientar a la clase dirigente. Con Sidicaro (1991) La Nación es un diario que, desde lo alto, mira la política. En este sentido, y con Martini (2000; 2002), entendemos que el diario se constituyó en una especie de pedagogo del sistema político argentino y sus instituciones. De carácter "liberal-conservador" el diario representa los intereses de un sector social oligárquico y agropecuario. Se trata de un espacio de discusión intelectual que se propuso formular un proyecto de ordenación del país, oscilando entre un apoyo al sistema democrático y otro tanto a la intervención de las fuerzas militares; bregando por cierto intervencionismo estatal (mientras no afectase sus propios intereses económicos) y un tímido reformismo social.

Discursivamente el diario construye un enunciatario de clase media alta o alta, capaz tanto de entender racionalmente lo acaecido en la sociedad, como de tomar decisiones en relación con los asuntos públicos (Martini, 2000). Los géneros periodísticos preponderantes en el diario fueron y son el noticioso y el de opinión. Además de difundir información de "fuentes fidedignas" (Martini, 2000), como apuesta particular del diario en el campo de la prensa gráfica; utiliza la prosa argumentativa en artículos de opinión que suelen presentarse a modo de posición a favor o en contra de los hechos o circunstancias según si éstos/as afectan o no el orden social instituido.

De formato sábana, con una tirada promedio de 160 mil ejemplares durante la semana La Nación es el segundo en cantidad de circulación de la Argentina (detrás de Clarín), y actúa como instalador de opinión tanto en la sociedad como en las instituciones y los demás medios masivos; como agente y agencia de noticias; fuente de primicias, y ocupa un lugar central en el mapa económico de los medios de comunicación.

\subsubsection{El País (España)}

El País, periódico español no deportivo de mayor difusión en España, no solo se publica Madrid sino también en Latinoamérica, donde se imprime y distribuye una edición Global.

El diario, perteneciente al mayor grupo mediático español, el GRUPO PRISA, fue fundado por José Ortega Spottorno. El periódico salió en circulación por vez primera el 4 de mayo de 1976, cuando comenzaba en España la transición española, una vez muerto Franco. El País fue el primer periódico de vocación demócrata de la Espala franquista, de ideología progresista, social-liberal, europeísta, y de centro-izquierda. La noche del 23 de febrero de 1981, se convirtió en el baluarte de la democracia española cuando ante el intento de golpe de estado del teniente coronel de la Guardia Civil Antonio Tejero, publicó una edición especial intitulada «El País, con la Constitución». Posicionándose sin titubeos en favor de la democracia, invitó a los 
ciudadanos a apoyarla aferrándose a los principios constitucionales. Durante la década de 1980, se consolidó como líder de la prensa española, frente a $A B C$, de tendencia conservadora.

El País, diario prestigioso, acata rigurosamente las normas periodísticas y mantiene normas internas de control de calidad. El Libro de Estilo del diario se convirtió en referencia obligada de periodistas en todo el mundo. Además, El País ha establecido, desde su fundación, acuerdos de colaboración con periódicos europeos socialdemócratas tales como La Repubblica de Italia, Le Monde Diplomatique, de Francia, y el International Herald Tribune.

En el aspecto formal, el diario tiende hacia una sobriedad expresiva, hecho que se manifiesta tanto en el tratamiento de la información como en la dimensión estético. Las páginas se presentan a cinco columnas en las que predomina una distribución armónica de los distintos subgéneros periodísticos. La fotografía y la infografía cumplen un papel secundario, de mero apoyo a la información escrita. En el año 2007, el diario renovó su formato y contenidos, incluyendo una serie de reformas que afectan tanto a su edición impresa como a su proyección digital en Internet, y sustituyó su histórico lema "Diario independiente de la mañana" por el de "El periódico global en español".

\subsection{Resultados}

Los hallazgos muestran similitudes y diferencias relevantes entre ambos diarios estudiados. Como primer dato relevante, no se hallaron artículos escritos por referentes de las Ciencias Sociales en la sección "Ciencia" de ninguno de los dos diarios en el periodo estudiado. Es decir, se comprueba que los diarios dedican solo el espacio de opinión para las presentaciones de los profesores de las Ciencias Sociales. Se analizaron exactamente 83 artículos de la sección "Opinión" de cada periódico siguiendo los lineamientos del análisis de contenido.

Tal como lo señaló Aurelio Arteta (2010), en una nota de opinión publicada en El País, y en función de lo aquí hallado, puede hipotetizarse que para ocupar espacios públicos de opinión tales como la prensa gráfica, los referentes sociales deben apoyarse en tres supuestos básicos. Por una parte, en que para hablar sobre ciertas áreas de la realidad solo cabe opinión, es decir, una argumentación (o conocimiento) capaz de persuasión y no de demostración rigurosa. Por la otra, en que lo opinable, relacionado con la conducta humana individual o colectiva, se encuadra en el terreno de la ética y la política. Por último, en que las opiniones, y las emociones que las argumentaciones suscitan, orientan el comportamiento humano en uno u otro sentido.

\subsubsection{Los temas que tratan los artículos...}

En La Nación, el $51 \%$ de los artículos hacen referencia a temas de Política Nacional. En su mayoría hacen alusión a las decisiones del gobierno y a los actores políticos involucrados con el gobierno nacional. El restante $40 \%$ hace alusión a otros temas y un $9 \%$ del Mercosur y situaciones de países limítrofes. 
Grafico 1. Los temas que tratan los artículos publicados en la sección Opinión de los diarios LA NACION y EL PAIS

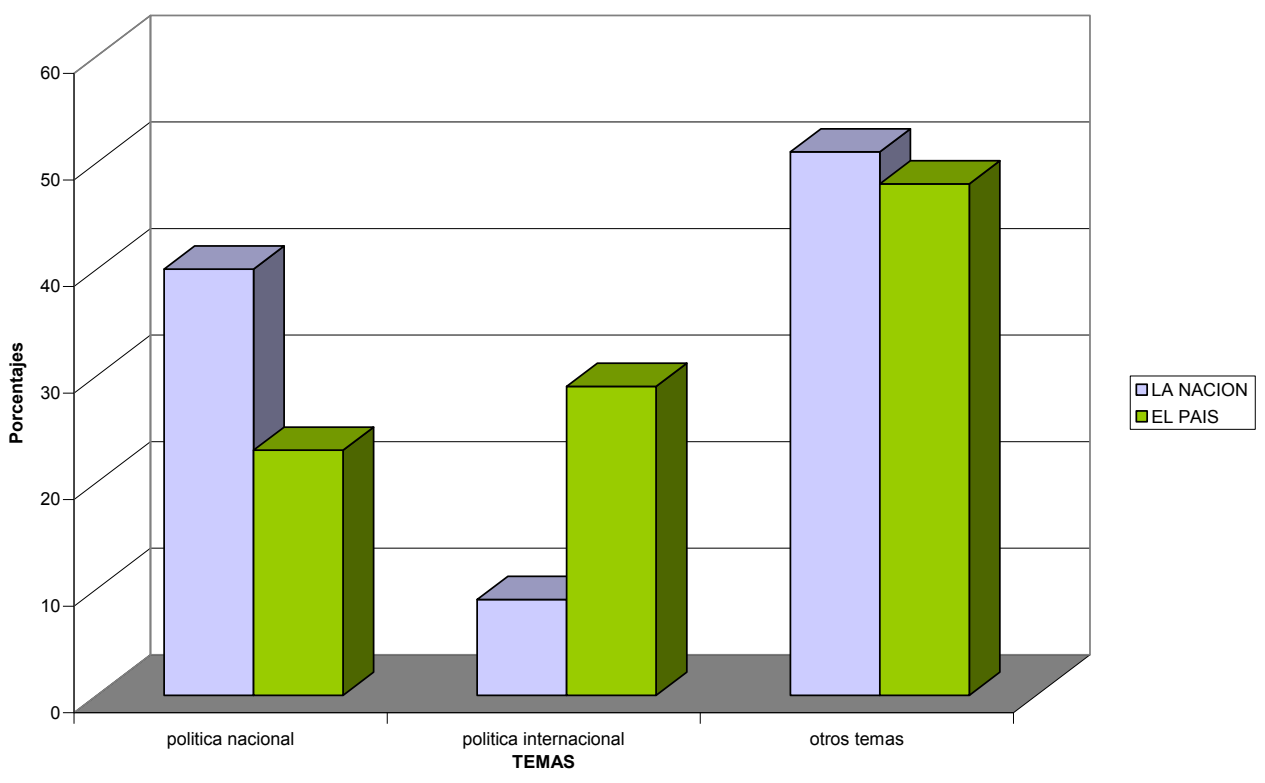

Mientras tanto, en El País, hallamos que el grupo más numeroso de artículos (un $48 \%$ del total de 83) hace referencia a otros temas no necesariamente relacionados con la Política Nacional. El segundo grupo numeroso, compuesto por algo más de $1 / 4$ de los artículos estudiados (un 29\%) está conformado por 24 artículos (escritos en su mayoría por catedráticos o cientistas sociales especializados) que tratan temas tales como la política internacional, con un especial énfasis en el análisis de la situación de los países latinoamericanos, México, los países árabes, Irán, Libia, Yemen, Siria); Estados Unidos; Cuba; Polonia, entre otros.

Por último, recién el tercer grupo numeroso de presentaciones, un 23\% tratan temas de política nacional (haciendo referencia a la política del gobierno de Zapatero, a las proyecciones hacia el futuro del país, a la cuestión de las tarifas eléctricas y a la crisis económica).Tanto en los artículos de política nacional como internacional se incluyen temas de ecología mundial. Hay muchas referencias a la catástrofe nuclear de Fukushima. Los restantes artículos, tratan sobre temas como la laicalización de España; la cuestión de la era digital, temas de ecología, la prevención de enfermedades como la malaria; las universidades y sus problemáticas, entre otros.

\subsection{2 ¿Qué profesión tienen los autores de los artículos de opinión?}

Mientras que para El País un 39\% de artículos analizados fueron escritos o por periodistas o por políticos de renombre internacional; para La Nación, tenemos un $40 \%$. El segundo grupo numeroso de artículos tanto para El País como para La Nación son aquellos redactados por Historiadores ó Especialistas en Ciencia Política ó Doctores en Economía, 27\% y $22 \%$ respectivamente. Un tercer grupo modal de 
artículos, para El País es el de aquellos que fueron redactados por escritores (un $18 \%)$; mientras tanto, para La Nación este tercer grupo queda conformado por los artículos escritos por abogados (17\%).

Cuadro 1. Autores de los artículos de opinión según su profesión.

\begin{tabular}{|l|c|c|c|c|}
\hline & \multicolumn{2}{|c|}{ EL PAIS } & \multicolumn{2}{c|}{ LA NACIÓN } \\
\hline & Cantidad & Porcentaje & Cantidad & Porcentaje \\
\hline Escritores & 12 & $18 \%$ & 6 & $10 \%$ \\
\hline Filósofos & 7 & $10 \%$ & 0 & $0 \%$ \\
\hline $\begin{array}{l}\text { Periodistas/políticos } \\
\text { de renombre } \\
\text { nacional o } \\
\text { internacional }\end{array}$ & 26 & $39 \%$ & 24 & $40 \%$ \\
\hline $\begin{array}{l}\text { Historiadores/Lic. } \\
\text { ciencias } \\
\text { política/economistas }\end{array}$ & 18 & $27 \%$ & 13 & $22 \%$ \\
\hline Sociólogos & 4 & $6 \%$ & 0 & $0 \%$ \\
\hline $\begin{array}{l}\text { Médicos psicólogos } \\
\text { Psico-pedagogos }\end{array}$ & 0 & $0 \%$ & 3 & $5 \%$ \\
\hline Abogados & 0 & $0 \%$ & 10 & $17 \%$ \\
\hline Otros & 0 & $0 \%$ & 4 & $7 \%$ \\
\hline & $100 \%$ & 60 & $100 \%$ \\
\hline
\end{tabular}

\subsubsection{Características de los referentes}

Entre las características de los referentes en las Ciencias Sociales encontramos que para el diario El País, el cuarto grupo numeroso de artículos fue publicado por filósofos (un 10\%). En definitiva, pareciera que El País de España privilegia publicar artículos de periodistas ó políticos reconocidos a nivel mundial; Luego, Doctores en Historia, especialistas en Ciencia Política (la mayoría con título de Doctor ó, lo que es igual, Ph. D) ó Doctores en Economía; y en tercer lugar, artículos de escritores o filósofos. 
Contrariamente, LA NACIÓN pareciera priorizar, en primer término, a las presentaciones de periodistas del medio; luego, a aquellas escritas por periodistas que son al mismo tiempo abogados y/o Lic. en Ciencia Política; en tercer lugar, a abogados o políticos ó licenciados en Ciencias políticas y/o Relaciones Internacionales; en cuarto lugar a Economistas.

EI PAÍS da lugar a la participación de catedráticos (profesores universitarios) que hacen investigación en las universidades más prestigiosas del mundo (Oxford, Harvard, Standford, Universidad de Barcelona; etc). Le da una un lugar aparentemente importante a la opinión de un grupo variado de profesionales las Ciencias Sociales (Ciencia Política, Economía Política, Historia, Comunicación y Sociología).

En el diario LA NACIÓN encontramos, contrariamente, que se le brinda un mayor espacio a lo que escriben los periodistas del mismo diario (es decir, a los periodistas locales), algunos historiadores, filósofos y escritores, pero también, y muy marcadamente a abogados (muchos de ellos periodistas de oficio).

De un total de 67 artículos escritos por referentes de las Ciencias Sociales en LA NACIÓN, solo 12 (apenas un 18\%) fueron escritos por docentes investigadores de universidades argentinas. De los 12 catedráticos, 5 fueron docentes-investigadores de la Universidad Torcuato Di Tella, doctorados en Ciencia Política y/o Relaciones Internacionales. Otros 3, fueron profesores ó de la Universidad Católica Argentina ó de la Universidad John F. Kennedy. En este grupo se encuentran un Prof. En Ciencia Política; un Prof. en Economía Internacional y otro en Derecho Constitucional. Solo 4 colaboradores pertenecen a las Universidades Nacionales y a CONICET (siendo los mismos Profesores de Historia y Profesores de Filosofía). Todos estos catedráticos poseen título máximo (Ph. D o Doctor) en alguna de las áreas de las Ciencias Sociales, pero provienen, en su mayoría, de universidades privadas, las cuales proveen, habitualmente, de profesionales que suelen formar parte del establishment gubernamental (políticos) ó de los grandes grupos económicos ('lobbies' e 'intelectuales'). Llama la atención, en LA NACIÓN, la poca colaboración de docentes investigadores originarios de las universidades públicas.

Esta tendencia de LA NACIÓN, pareciera coincidir con la política editorial del diario a lo largo del tiempo. Si bien, en 1909, el diario LA NACIÓN se propuso abandonar el periodismo de doctrina para pasar al periodismo informativo y/o de explicación, en el diario escriben con mayor frecuencia especialistas en ciencia política y derecho. Los que opinan, opinan en relación a la política nacional, desde una perspectiva que evalúa el funcionamiento de los órganos institucionales; los poderes y el orden democrático. Si tenemos en cuenta que LA NACIÓN es un aparato ideológico de la sociedad civil que contribuye a generar cierta hegemonía político-intelectual-cultural, podríamos señalar que quienes escriben en el diario en parte dan cátedra y cumplen un rol de adoctrinamiento social. 


\subsubsection{Los perfiles}

En esta comparación incluimos un aspecto que consideramos destacado: la Dirección de EL PAIS creó la figura del Defensor del Lector con el objetivo de garantizar los derechos de los lectores, atender a sus dudas, quejas y sugerencias en relación con los contenidos del periódico. El diario español está abierto a la participación de cualquier lector por iniciativa propia en cualquier instancia. Cuenta con aspectos que van desde la ética periodística, la crisis de la prensa, las puertas abiertas, los lectores nos corrigen, los debates de periodismo y los lectores hablan de periodismo para mejorar la calidad del tratamiento de las informaciones. Mientras tanto, LA NACION sólo exhibe una sección de carta de lectores, donde, en la mayoría de los casos, se publican notas de lectores que presentan una minúscula controversia o diferencia con el tratamiento de las informaciones.

EI PAIS posee una alta calidad de textos, que incluye conceptos, datos y relaciones lógicas, donde puede apreciarse claramente la exigencia individual, de supervisión y de formación, mientras que en LA NACION el contenido proporciona argumentaciones marcadas por una fuerte impregnación ideológica o cultural editorial y del autor, donde determinados temas (en especial los de política nacional) contienen información excesivamente sesgada por la opinión del referente.

\section{CONCLUSIONES}

Cada vez que reflexionamos sobre el espacio que ocupan las Ciencias Sociales en los diarios constatamos la misma referencia inobjetable: sólo opinión, para los dos diarios aquí examinados. La sección ciencia es ocupada por entrevistas o artículos de periodismo científico de las jerarquizadas ciencias duras y las biomédicas. Un indicador elocuente es la facultad de rectificación con que se bendice a las dos últimas, pero se condena en las primeras. Que las ciencias duras y sobre todo las biomédicas hayan trabajado en el avance científico, no es problema, sino el hecho de que las Ciencias Sociales tienen vedado el reconocimiento a nuevos descubrimientos y estadíos científicos superiores. Entonces, el periódico sigue adoptando un criterio cientificista, atemporal y positivista, hecho poderosos y poco inocente, pues el mismo depende de los mecanismos de financiamiento y la privatización de la decisión política, todo lo cual re-significa el conocimiento tornándolo en mercancía.

Todo lo anterior, indica que debe tenerse una visión más clara de qué son, en qué fase de desarrollo están y en qué circunstancias institucionales se practican las Ciencias Sociales, en especial la investigación socio científica en los distintos países para buscar obtener una mejor posición. Y los medios de comunicación deberían poder canalizar la divulgación, la valoración y la visibilidad de la investigación científica social, puesto que es ella la que permite entender los cambios permanentes que afectan tanto a los investigadores de la biomedicina y las ciencias duras como a aquellos de las Ciencias Sociales y Humanas, así como también a su producción de conocimiento.

En síntesis: 
- Los criterios de selección muestran un escaso reconocimiento de las Ciencias Sociales y sus avances.

- De acuerdo al espacio y el reconocimiento son calificadas como conocimiento capaz de persuasión y no de demostración rigurosa, que encuadra en el territorio de la ética y la política.

- La opinión pública se beneficia más con los artículos de los referentes que escriben en EL PAIS que con aquellos que aparecen publicados en LA NACION, por su contenido y orientación.

- $\quad$ El contexto en el cual se exhiben los artículos responde al tiempo político y social que suele convertirse en una presentación justificable de determinados temas. En LA NACION encontramos que en algunos casos las argumentaciones no tienen una base académica sólida.

Si bien la objetividad se contrapone con la ideas de los precursores que antes trabajaron los temas argumentados, no debemos caer en la creencia de que no hay diferencia entre la subjetividad ideal y una interpretación totalmente moldeada por la subjetividad de quien escribe, y que esta se relaciona tanto con los editores como con la política de los medios. Entonces, cabe preguntarnos ipor qué la política de los medios nos presenta como inmutable el lugar de los artículos de especialistas de las Ciencias Sociales en opinión? ¿Además, por qué los aportes de los científicos sociales responden, mayoritariamente, a una estructura textual argumentativa de opinión? El periodismo científico, ¿no incluye los aportes de las investigaciones provenientes del campo de las Ciencias Sociales? ¿Los investigadores de las Ciencias Sociales, no producen acaso conocimiento científico? Y sobre todo, ¿por qué las ciencias duras y la medicina merecen un espacio más destacado que las Ciencias Sociales en la prensa gráfica? Tanto un periódico de tradición abierta y progresista como El País como un diario de estructura conservadora, como la Nación, aplican políticas de medios que contribuyen a reforzar la idea generalizada de sentido común que otorga, a las ciencias duras, un lugar de superioridad en relación con las sociales. ¿Es acaso, que los conocimientos sobre el mundo social no constituyen una fuente de enseñanza y aprendizaje? O más bien, las políticas de los medios ¿están dispuestas a reconocer el avance y la vital importancia en las sociedades actuales del conocimiento producido por las Ciencias Sociales?

\section{REFERENCIAS}

Accardo, A. y Philippe C. (1989): La sociología de Bourdieu. Traducción del francés por José Manuel García. Facultad de Filosofía y Humanidades, UNC. Córdoba, Argentina. Págs. 171.

Arteta, A. (2011): "En boca cerrada" en El País, sección Opinión. 17/11/2011. Disponible en:

http://www.elpais.com/articulo/opinion/boca/cerrada/elpepuopi/20101117elpepiopi_4/ Tes

Bergés, L. (2010): "Poder político, económico y comunicativo en la sociedad 
neoliberal" en Revista Latina de Comunicación Social, 65. La Laguna (Tenerife). Universidad de La Laguna. Págs. 244 a 254. Recuperado el 1 de abril de 2011 en : http://www.revistalatinacs.org/10/art2/897_UAB/19_Laura.html DOI: $10.4185 /$ RLCS-65-2010-897-244-254

Bourdieu, P. (2003): Por una sociología clínica del campo científico. Los usos sociales de la ciencia. $1^{\circ}$ Edición. $1^{\circ}$ Reimpresión. Nueva Visión. Buenos Aires.

Bourdieu, P. y Wacquant, L. (1992): Respuestas por una antropología reflexiva. Grijalbo. México.

Cabeza, P.; Riffo, D. y Sanhueza, O. (2008): Antecedentes para la elaboración de un proyecto destinado a crear un magíster de divulgación social de la ciencia en el Departamento de Comunicación Social de la Universidad de Concepción. Universidad de Concepción. Concepción.

Cabrera, S. y Aguilera, M. (2005): "La divulgación científica bajo el microscopio de las Ciencias Sociales" en Estudio de Periodismo, № 9. Universidad de Concepción. Disponible en:

http://www.periodismoudec.cl/estudiosdeperiodismo/index.php?option=com_content\& task=view\&id=48\&Itemid=54 (05/05/2010).

Calvo, M. H. (2006): "Conceptos sobre difusión, divulgación, periodismo y comunicación", en www.manuelcalvohernando.es/articulo.php?id=8

De Mateo, R. y Bergés, L. (2009): Los retos de la televisión pública. Comunicación Social. Sevilla/Zamora.

EC (1994): Europa y la sociedad global de la información (Bangemann Report). Brussels.

Echevarría, B. (1998): "Por qué hablar hoy de género periodísticos" en Comunicación y Estudios Universitarios. N8. 1998. págs. 9-14.

Echeverría, J. (2005): "La revolución tecnocientífica". En Revista CONfines. Instituto Tecnológico y de Estudios Superiores de Monterrey. México.

Eco, H. (1987): Lector in fabula. Ed. Lumen. Barcelona.

Gomis, L. (1991): Teoría del periodismo. Paidós. Barcelona.

Gore, A. (1994): "Forging a new Athenian Age of democracy" en Intermedia, №2 (22). ICC. Londres.

Gramsci, A. (1977): Escritos políticos (1917-1933). Siglo XXI. México.

Gramsci, A. (1984): Los intelectuales y la organización de la cultura. Nueva Visión. 
Buenos Aires.

Hernández, R.; Fernández, F.C. y Baptista, P.B. (2000): Metodología de la Investigación. Segunda Edición. Mc. Graw Hill. Buenos Aires.

Lulo, J. y Schuster, Federico (2002): Filosofía y métodos de las Ciencias Sociales.

Martinelli, A. (2010): "Social science in the public space" en World Social Science Report. Knowledge divides. $1^{0}$ Edición. Unesco Publishing. París.

Martini, S. (1999): "El sensacionalismo y las agendas sociales" en Diálogos de la comunicación, No 55, FELAFACS.

Martini, S. (2000): Periodismo, noticia y noticiabilidad. Buenos Aires, Norma.

Martini, S. (2002): "Agendas policiales de los medios en la Argentina: la exclusión como un hecho natural" en Gayol y Kessler, G. (Comps.). Violencias, delitos y justicias en la Argentina. Manantial/ Univ. Nacional de Gral. Sarmiento. Buenos Aires.

Muñoz, B. (1995): Teoría de la Pseudocultura. Estudios de sociología de la cultura y de la comunicación de masas. Editorial Fundamentos. Buenos Aires.

Navarro, P. y Díaz, C. (2007): "Análisis de contenido" en Delgado y Gutiérrez (Coords.): Métodos y Técnicas cualitativas de investigación en Ciencias Sociales (pp.177-224). Editorial Síntesis. Madrid.

Ortega, F. y Humanes, M. L. (2000): Algo más que periodistas. Sociología de una profesión. Ariel. Madrid.

Pintos, J. (2011) "Apuntes para una teoría: los "medios", la "realidad" y la "alternativa local" en Revista Latina de Comunicación Social, No 36. La Laguna, Tenerife. Disponible en: http://www.ull.es/publicaciones/latina (13/03/2011).

Prenafeta, S. (2008). La Comunicación de la Ciencia en Chile. Message. Santiago de Chile.

Rost, A. (2003). "Periodismo de Explicación". En Red-acción, sitio web del Área Periodismo de la Facultad de Derecho y Ciencias Sociales. General Roca: Universidad Nacional del Comahue.

http://redaccion.uncoma.edu.ar/asignaturas/periodismoexplicacion.htm

SECYT (2007): "La percepción de los argentinos sobre la investigación científica en el país, Informe Final de la Segunda Encuesta Nacional de Percepción Pública de la Ciencia". Observatorio Nacional de Ciencia, Tecnología e Innovación Productiva, Secretaría de Ciencia, Tecnología e Innovación Productiva (SECTIP), Argentina. Disponible en: http://www.observatorio.secyt.gov.ar/ 
Sidicaro, R. (1991): La política mirada desde arriba. Las ideas del Diario La Nación1909-1989. Editorial Sudamericana. Buenos Aires.

Sierra, R. (1996): Tesis doctorales y trabajos de investigación científica: metodología general de su elaboración y documentación. Paraninfo Ed. Madrid.

Tenti, E. (2007): La escuela y la cuestión social. Ensayos de sociología de la educación. Primera Edición. Siglo XIX. Buenos Aires.

UNESCO (2010): "Social sciences, education and society" en World Social Science Report. Knowledge divides. $1^{\circ}$ Edición. Unesco Publishing. París.

Vasilachis, I. (1997): Discurso político y prensa escrita. Gedisa. Barcelona.

Verón, E. (1983): Construir el acontecimiento. Los medios de comunicación masiva y el accidente en la central nuclear de Three Mile Island. Ed. Gedisa. Barcelona.

Verón, E. (1991): "Les médias en réception: les enjeux de la complexité" en MEDIASPOUVOIRS, № 21, Ja-Févr-Mar.

Verón, E. (1993): La semiosis social. Fragmentos de una teoría de la discursividad. Editorial Gedisa. Barcelona.

\section{Cecilia Blanco Berrone}

Magíster en Ciencias Sociales y Licenciada en Comunicación Social con mención en Investigación y Planeamiento en Ciencias Sociales por la UNC. Se encuentra cursando el Doctorado en Comunicación Social en la ECI y el Doctorado en Estudios Sociales de América Latina, en el Centro de Estudios Avanzados (CEA), ambos en la UNC. Ha realizado un Posgrado en Estadística Aplicada a la Investigación, en la FCE, de la UNC. Se desempeña como docente investigadora en la ECI, desde el año 2004. En la actualidad dicta clases en las cátedras Metodología de la Investigación Aplicada a la Comunicación e Introducción a la Comunicación Social. Se ha desempeñado, además, en las asignaturas Antropología Sociocultural, Seminario de Tesis, y Seminario de Apoyo a Trabajos Finales. Es autora del libro: Encuesta y Estadística: métodos de investigación cuantitativa en Ciencias Sociales y Comunicación, Editorial Brujas, Córdoba, Argentina, año 2011. Miembro de varios equipos de investigación en la Facultad de Filosofía y Humanidades (FFyH) y en la ECI de la UNC. En la actualidad, se encuentra abocada al estudio de la conformación del campo académico de la comunicación social en el marco de la ECI, UNC; de la disputa epistemológica en torno a la conformación teórica del campo; del perfil de comunicador que propone la currícula de enseñanza de la institución.

\section{Liliana E. Pereyra Gómez}

Graduada de la Facultad de Ciencias Económicas (F.C.E.) de la Universidad Nacional de Córdoba (U.N.C) como Licenciada en Economía. Especialista en Estudios Sociales, por el Centro de Estudios Avanzados (CEA) de la U.N.C. Ha cursado estudios en la 
Maestría en Ciencias Sociales, de la Facultad de Derecho y Ciencias Sociales y en el Doctorado en Estudios Sociales de América Latina en el CEA (U.N.C). Se desempeña actualmente en la F.C.E., U.N.C, como Profesora Asistente en Introducción a las Ciencias Sociales y en Principios y Estructura de la Economía. Es investigadora del Instituto de Economía y Finanzas de la F.C.E. y presenta un interesante caudal de publicaciones sobre temas de pobreza, exclusión y medio ambiente. Coautora del libro "Las raíces del delito en Argentina. Mapa, Modelos y Políticas Alternativas" (2010). Expositora en Congresos, Seminarios y Jornadas nacionales e internacionales. Autora de artículos publicados en la prensa local. 